Article

\title{
Sensory Quality Evaluation of Korla Pear from Different Orchards and Analysis of Their Primary and Volatile Metabolites
}

\author{
Yuan Liu ${ }^{1,2}$, Simin Xiang ${ }^{1,2}$, Haipeng Zhang ${ }^{1}$, Hongyan Zhang ${ }^{1,2}$, Cuiyun Wu ${ }^{3,4}$, \\ Zhanghu Tang ${ }^{5}$, Jiangbo Wang ${ }^{3,4, *}$ and Juan $\mathrm{Xu}{ }^{1,2, * \mathbb{D}}$
}

1 Key Laboratory of Horticultural Plant Biology (Ministry of Education), College of Horticulture and Forestry Sciences, Huazhong Agricultural University, Wuhan 430070, China; luiyuer@webmail.hzau.edu.cn (Y.L.); ansimiy@163.com (S.X.); haipengzhang@webmail.hzau.edu.cn (H.Z.); zhanghy@mail.hzau.edu.cn (H.Z.)

2 Research Group on Sensory Evaluation and Consumer Preference of Horticultural Products, College of Horticulture and Forestry Sciences, Huazhong Agricultural University, Wuhan 430070, China

3 The National and Local Joint Engineering Laboratory of High Efficiency and Superior-Quality Cultivation and Fruit Deep Processing Technology of Characteristic Fruit Trees in South Xinjiang, College of Plant Science, Tarim University, Alar 843300, China; wcyby@163.com

4 Xinjiang Production and Construction Corps Key Laboratory of Biological Resources Protection and Utilization in Tarim Basin, Alar 843300, China

5 National Fruits Germplasm Resources Garden of Xinjiang Academy of Agricultural Sciences in Luntai, Luntai 841600, China; ligu@webmail.hzau.edu.cn

* Correspondence: 120030034@taru.edu.cn (J.W.); xujuan@mail.hzau.edu.cn (J.X.); Tel.: +27-87286965 (J.X.)

Received: 28 September 2020; Accepted: 25 November 2020; Published: 27 November 2020

check for updates

\begin{abstract}
Metabolites play vital roles in shaping the quality of fresh fruit. In this study, Korla pear fruit harvested from twelve orchards in South Xinjiang, China, were ranked in sensory quality by fuzzy logic sensory evaluation for two consecutive seasons. Then, gas chromatography-mass spectrometry (GC-MS) was applied to determine the primary metabolites and volatile compounds. Sensory evaluation results showed that the panelists were more concerned about 'mouth feel' and 'aroma' than about 'fruit size', 'fruit shape' and 'peel color'. In total, 20 primary metabolites and 100 volatiles were detected in the pear fruit. Hexanal, (E)-2-hexenal, nonanal, D-limonene, (Z)-3-hexen-1-yl acetate and hexyl acetate were identified as the major volatile compounds. Correlation analysis revealed that L-(+)-tartaric acid, hexanoic acid, trans-limonene oxide and 2,2,4-trimethyl-1,3-pentanediol diisobutyrate were negatively correlated with sensory scores. Furthermore, OPLS-DA results indicated that the fruit from three orchards with lower ranks in quality could be distinguished from other samples based on the contents of L-(+)-tartaric acid and other eight metabolites, which were all associated with 'mouth feel' and 'aroma'. This study reveals the metabolites that might be closely associated with the sensory quality attributes of Korla pear, which may provide some clues for promoting the fruit quality in actual production.
\end{abstract}

Keywords: metabolites; Korla pear fruits; sensory evaluation; fuzzy logic model

\section{Introduction}

Korla pear (Pyrus sinkiangensis $\mathrm{Yu}$ ) is a distinctive and economic cultivar widely planted in Xinjiang, China, and is popular among domestic consumers due to its unique flavor, refreshing taste and crispy texture. Moreover, a large amount of Korla pear fruit are exported to foreign countries every year. However, the quality of Korla pear is hardly unified due to the vast planting territory in Xinjiang region with varied climate and soil conditions. 
Aroma and taste are important indicators of fruit quality, and are closely related to fruit metabolites due to the complex interactions between metabolites and human senses. Metabolites such as soluble sugars, organic acids and volatiles play important roles in fruit sensory quality. Although there has been extensive research on the metabolites in different pear cultivars [1-7], few studies were focused on the fruit sensory quality and relevant metabolites of Korla pear [8-11]. In Korla pear, aldehydes and esters such as hexanal and hexyl acetate are dominant volatile compounds [8,12,13]; while fructose and malic acid are the major soluble sugar and organic acid, respectively [3,5]. Compared with other pear cultivars, Korla pear has a higher sugar/acid ratio that contributes to its excellent taste [3].

Sensory evaluation plays a vital role in the assessment of food preference. Combination of chemical and statistical analysis with sensory evaluation can well demonstrate the association between the sense and compounds in food. Since information acquired from human senses cannot enable precise quantitative assessment, fuzzy logic has been employed for more reasonable ranking of food samples [14-16]. It has become a commonly used method for the sensory evaluation of foods such as beverages and tea products [17-19]. Nevertheless, it has only been applied to the sensory evaluation of a limited number of fresh fruit varieties [20-22], and is more often used to explore the correlations between sensory evaluation results and food chemical compounds [23-26]. In this study, we attempted to firstly evaluate the sensory quality attributes of Korla pear from 12 orchards, and then determined the primary and volatile metabolites. Finally, the pear fruit samples were ranked according to the sensory scores to determine whether the sensory quality attributes are related to the production areas and some key metabolites. The findings may help the regionalized planting of Korla pear in Xinjiang on the basis of fruit quality and sensory quality attributes, and provide theoretical support to promote and stabilize the fruit quality in actual production.

\section{Results}

\subsection{Sensory Evaluation of Korla Pear}

In the two seasons, the sensory scores of all samples were given by the panelists and presented in the Supplementary Material (Table S1). Triplets were obtained for the ranking of various sensory quality attributes (Table S2). The triplets for the overall quality scores of the samples were then generated in Table S3 based on the data in Tables S1 and S2. The values of overall membership function of sensory scores for all pear samples are presented in the Supplementary Material (Table S4), which were then used together with standard fuzzy scale to calculate the similarity values. The samples were graded on the standard fuzzy scale based on the maximum similarity values. Finally, pear fruit from different orchards within a same grade were ranked from 1 to 12 based on the similarity values (Table 1).

Table 1. Similarity values for pear samples.

\begin{tabular}{cccccccc}
\hline Sample & $\begin{array}{c}\text { F1/Not } \\
\text { Satisfactory }\end{array}$ & F2/Fair & F3/Satisfactory & F4/Good & F5/Very Good & F6/Excellent & Rank \\
\hline S1 & & & & & & & \\
S2 & 0.014 & 0.171 & 0.465 & $\mathbf{0 . 6 8 3}$ & 0.544 & 0.169 & 9 \\
S3 & 0.024 & 0.226 & 0.534 & $\mathbf{0 . 6 8 7}$ & 0.452 & 0.119 & 7 \\
S4 & 0.025 & 0.237 & 0.564 & $\mathbf{0 . 7 0 5}$ & 0.430 & 0.096 & 1 \\
S5 & 0.016 & 0.186 & 0.488 & $\mathbf{0 . 6 9 0}$ & 0.513 & 0.151 & 5 \\
S6 & 0.008 & 0.136 & 0.409 & $\mathbf{0 . 6 5 9}$ & 0.597 & 0.199 & 12 \\
S7 & 0.021 & 0.212 & 0.525 & $\mathbf{0 . 6 9 4}$ & 0.463 & 0.122 & 3 \\
S8 & 0.018 & 0.193 & 0.492 & $\mathbf{0 . 6 8 8}$ & 0.507 & 0.147 & 6 \\
S9 & 0.048 & 0.310 & 0.652 & $\mathbf{0 . 6 7 5}$ & 0.317 & 0.037 & 11 \\
S10 & 0.026 & 0.238 & 0.550 & $\mathbf{0 . 6 8 5}$ & 0.441 & 0.114 & 8 \\
S11 & 0.020 & 0.207 & 0.517 & $\mathbf{0 . 6 9 1}$ & 0.469 & 0.127 & 4 \\
S12 & 0.014 & 0.180 & 0.494 & $\mathbf{0 . 7 0 4}$ & 0.512 & 0.143 & 2 \\
\hline
\end{tabular}


Table 1. Cont.

\begin{tabular}{cccccccc}
\hline Sample & $\begin{array}{c}\text { F1/Not } \\
\text { Satisfactory }\end{array}$ & F2/Fair & F3/Satisfactory & F4/Good & F5/Very Good & F6/Excellent & Rank \\
\hline S1 & & & & 2019 & & & \\
S2 & 0.024 & 0.254 & 0.630 & $\mathbf{0 . 7 2 1}$ & 0.373 & 0.057 & 5 \\
S3 & 0.005 & 0.139 & 0.462 & $\mathbf{0 . 7 1 0}$ & 0.559 & 0.167 & 6 \\
S4 & 0.024 & 0.244 & 0.594 & $\mathbf{0 . 7 0 9}$ & 0.411 & 0.087 & 7 \\
S5 & 0.030 & 0.296 & 0.693 & $\mathbf{0 . 6 9 8}$ & 0.279 & 0.023 & 9 \\
S6 & 0.022 & 0.241 & 0.610 & $\mathbf{0 . 7 2 2}$ & 0.399 & 0.074 & 4 \\
S7 & 0.033 & 0.307 & $\mathbf{0 . 6 8 3}$ & 0.663 & 0.302 & 0.090 & 11 \\
S8 & 0.038 & 0.311 & $\mathbf{0 . 6 8 2}$ & 0.675 & 0.28 & 0.026 & 12 \\
S9 & 0.039 & 0.318 & $\mathbf{0 . 6 8 6}$ & 0.666 & 0.279 & 0.027 & 10 \\
S10 & 0.019 & 0.221 & 0.578 & $\mathbf{0 . 7 2 6}$ & 0.430 & 0.09 & 3 \\
S11 & 0.026 & 0.264 & 0.635 & $\mathbf{0 . 7 0 8}$ & 0.365 & 0.058 & 8 \\
S12 & 0.007 & 0.162 & 0.518 & $\mathbf{0 . 7 4 1}$ & 0.486 & 0.112 & 1 \\
\hline
\end{tabular}

Note: bold numbers are the maximum similarity values of pear samples on the standard fuzzy scale.

In 2018, S3 in the Akesu district and S11 in the Kuerle district ranked the top, while S5 in the Kuerle district ranked the last. In 2019, S11 in the Kuerle district and S12 in the Akesu district ranked the top, and S7 in the Akesu district was the last.

Sensory quality attributes were ranked based on the triplets by the same methods. The corresponding similarity values were compared (Table S5). 'Mouth feel' and 'aroma' ranked the top two in both 2018 and 2019, suggesting that flavor has great contribution to the preference of consumers for Korla pear.

\subsection{Primary Metabolites in Korla Pear}

Primary metabolites in the pulp of Korla pear harvested in 2018 were analyzed by using GC-MS (Table 2). As a result, seven amino acids, four organic acids, two fatty acids and seven sugars were detected (Table S6). In addition to the high content of malic acid and fructose, glucitol was also detected at a high level of 12.17-24.34 mg/g. Shikimic acid was undetectable. L-(+)-Tartaric acid was detected at a level of $2.36-7.79 \mu \mathrm{g} / \mathrm{g}$, but it was rarely counted in most studies due to its low concentration. Galactose was detected at a level of $0.14-0.30 \mathrm{mg} / \mathrm{g}$, while it was not considered in most studies owing to its low sweetness value [5,6]. The sugar/acid ratio of Korla pear ranged from 42.06 to 74.03, which was higher than that of many other pear varieties such as Dangshan, Yali and Nanguo pear cultivars [2,3,5], and thus might greatly contribute to its excellent quality [3].

Table 2. Primary metabolites detected in the pulp of Korla pear fruit by using GC-MS.

\begin{tabular}{|c|c|c|c|c|c|}
\hline \multirow{2}{*}{ Compounds } & \multirow{2}{*}{ RT } & \multicolumn{4}{|c|}{ Concentration $(\mu \mathrm{g} / \mathrm{g}$ FW) } \\
\hline & & Maximum & Sample & Minimum & Sample \\
\hline \multicolumn{6}{|l|}{ Amino acid } \\
\hline L-Valine & 6.11 & $5.36 \pm 0.29$ & $\mathrm{~S} 12$ & $0.30 \pm 0.25$ & S6 \\
\hline L-Isoleucine & 8.12 & $1.01 \pm 0.07$ & $\mathrm{~S} 12$ & - & S6 \\
\hline L-Proline & 9.21 & $37.26 \pm 0.70$ & $\mathrm{~S} 12$ & $11.93 \pm 0.98$ & S6 \\
\hline Serine & 10.18 & $4.75 \pm 0.21$ & $\mathrm{~S} 12$ & $0.05 \pm 0.07$ & S5 \\
\hline L-Threonine & 11.00 & $2.81 \pm 0.03$ & $\mathrm{~S} 12$ & $0.02 \pm 0.00$ & S3 \\
\hline L-Aspartic acid & 15.67 & $52.88 \pm 5.89$ & $\mathrm{~S} 12$ & $1.32 \pm 0.70$ & S5 \\
\hline L-Glutamic acid & 19.24 & $4.73 \pm 0.10$ & $\mathrm{~S} 12$ & $0.09 \pm 0.05$ & S6 \\
\hline \multicolumn{6}{|l|}{ Organic acids } \\
\hline Malic acid & 14.61 & $1809.13 \pm 420.52$ & S8 & $600.20 \pm 25.76$ & S9 \\
\hline $\mathrm{L}-(+)$-Tartaric acid & 18.51 & $7.79 \pm 1.81$ & S8 & $2.36 \pm 0.24$ & $\mathrm{~S} 2$ \\
\hline Citric acid & 26.21 & $31.40 \pm 2.27$ & S11 & $12.35 \pm 1.10$ & S9 \\
\hline Quininic acid & 27.46 & $212.43 \pm 162.28$ & $\mathrm{~S} 10$ & $105.39 \pm 20.03$ & S11 \\
\hline
\end{tabular}


Table 2. Cont.

\begin{tabular}{|c|c|c|c|c|c|}
\hline \multirow{2}{*}{ Compounds } & \multirow{2}{*}{ RT } & \multicolumn{4}{|c|}{ Concentration $(\mu \mathrm{g} / \mathrm{g}$ FW) } \\
\hline & & Maximum & Sample & Minimum & Sample \\
\hline \multicolumn{6}{|l|}{ Fatty acids } \\
\hline Palmitic Acid & 34.41 & $14.20 \pm 8.54$ & S11 & $3.64 \pm 2.93$ & S6 \\
\hline Stearic acid & 44.07 & $15.05 \pm 9.92$ & $\mathrm{~S} 11$ & $1.93 \pm 1.71$ & S6 \\
\hline \multicolumn{6}{|l|}{ Sugars } \\
\hline D-(-)-Fructofuranose & 25.77 & $18492.86 \pm 4309.41$ & S8 & $11285.72 \pm 359.93$ & S4 \\
\hline Fructose & 26.07 & $20999.04 \pm 4646.51$ & S8 & $12012.71 \pm 22.17$ & S4 \\
\hline Psicopyranose & 27.11 & $11453.29 \pm 2590.96$ & S8 & $6820.89 \pm 394.51$ & S4 \\
\hline Glucose & 28.81 & $13910.25 \pm 3120.71$ & S8 & $8145.27 \pm 138.45$ & $\mathrm{~S} 2$ \\
\hline$d$-Galactose & 29.31 & $303.88 \pm 47.85$ & S8 & $139.70 \pm 96.73$ & S11 \\
\hline D-Glucitol & 30.26 & $24335.64 \pm 5912.74$ & S8 & $12171.03 \pm 8458.33$ & S11 \\
\hline Sucrose & 48.42 & $2968.10 \pm 246.14$ & S6 & $1900.73 \pm 168.91$ & S12 \\
\hline Total Amino acid & & $108.82 \pm 5.90$ & $\mathrm{~S} 12$ & $14.65 \pm 2.93$ & S6 \\
\hline Total acid & & $1099.01 \pm 41.92$ & S10 & $806.63 \pm 60.89$ & S9 \\
\hline Total sugar & & $91705.26 \pm 20996.43$ & $\mathrm{~S} 8$ & $56878.51 \pm 2251.72$ & $\mathrm{~S} 4$ \\
\hline Sugar/Acid & & 74.03 & S9 & 42.06 & S11 \\
\hline
\end{tabular}

\subsection{Volatiles in Korla Pear}

The volatiles were profiled in the peels of Korla pear harvested in 2018 from 12 orchards (Table S7). Although more than 200 volatile compounds had been reported in Korla pear [8-10,12,13,27], there exist varies between different Korla pear samples. A total of 100 volatile compounds were detected in this article, including nine aldehydes, 20 esters, 12 alcohols, 19 terpenes and 40 other volatiles such as alkanes. Aldehydes were the most abundant compounds among the volatiles (Table 3). A wide variety of esters were detected despite of their low contents. For example, hexyl acetate was detected at $82.43-818.52 \mu \mathrm{g} / \mathrm{kg}$. Many of them such as hexyl acetate usually contribute to the impression of 'fruity' in sensory evaluation [12]. A number of terpenes which were usually detected at high concentrations in citrus essential oil were also detected in Korla pear. The concentrations of $\mathrm{D}$-limonene and $\alpha$-farnesene were $34.16-937.00 \mu \mathrm{g} / \mathrm{kg}$ and $0.00-277.18 \mu \mathrm{g} / \mathrm{kg}$. In general, hexanal, $(E)-2$-hexenal, nonanal, D-limonene, (Z)-3-hexen-1-yl acetate and hexyl acetate were abundant. For pear fruit harvested from different orchards, the volatile profiles showed great variations. On average, the number of compounds detected in the pear fruit from all 12 orchards was 69 . However, only 34 compounds were commonly detected in all samples, whereas seven were unique in pear fruit from certain orchards (Table S8). For example, tetradecanoic acid was only detected in S12 with a concentration of $1225.67 \pm 825.43 \mu \mathrm{g} / \mathrm{kg}$.

Table 3. Volatile compounds detected in Korla pear from 12 orchards.

\begin{tabular}{cccc}
\hline Compounds & Retention Index (RI) & $\begin{array}{c}\text { Concentration Range } \\
(\mu \mathrm{g} / \mathbf{k g} \text { FW) }\end{array}$ & $\begin{array}{c}\text { Average Concentration } \\
(\boldsymbol{\mu g} / \mathbf{k g} \text { FW)/Percentage } \\
\text { of Total Volatiles (\%) }\end{array}$ \\
\hline Aldehydes & & $10222.35-75589.04$ & $26133.94 / 85.84$ \\
Hexanal & 800 & $3472.75-35617.72$ & $12954.25 / 42.55$ \\
$(E)-2-H e x e n a l$ & 854 & $2782.32-39086.40$ & $12666.51 / 41.60$ \\
Octanal & 1003 & $0.00-318.75$ & $39.06 / 0.13$ \\
Nonanal & 1104 & $211.58-798.32$ & $416.57 / 1.37$ \\
Decanal & 1206 & $7.91-144.89$ & $28.74 / 0.09$ \\
Tetradecanal & 1416 & $7.74-66.02$ & $17.15 / 0.06$ \\
1-Pentadecanal & 1613 & $0.16-41.36$ & $6.50 / 0.02$ \\
Hexadecanal & 1715 & $0.00-23.41$ & $2.82 / 0.01$ \\
Esters & 1817 & $0.00-24.99$ & $2.35 / 0.01$ \\
& & $\mathbf{3 6 1 . 8 2 - 3 2 0 6 . 4 5}$ & $\mathbf{1 3 1 4 . 4 7 / 4 . 3 2}$ \\
\hline
\end{tabular}


Table 3. Cont.

\begin{tabular}{|c|c|c|c|}
\hline Compounds & Retention Index (RI) & $\begin{array}{c}\text { Concentration Range } \\
(\mu \mathrm{g} / \mathrm{kg} \text { FW })\end{array}$ & $\begin{array}{c}\text { Average Concentration } \\
(\mu \mathrm{g} / \mathrm{kg} \text { FW)/Percentage } \\
\text { of Total Volatiles }(\%)\end{array}$ \\
\hline Methyl hexanoate & 925 & $0.00-11.27$ & $1.62 / 0.01$ \\
\hline Acrylic acid isoamyl ester & 940 & $3.61-24.71$ & $10.80 / 0.04$ \\
\hline Ethyl hexanoate & 1000 & $0.00-5.12$ & $0.85 /-$ \\
\hline (Z)-3-Hexen-1-yl acetate & 1005 & $152.86-2501.62$ & $780.49 / 2.56$ \\
\hline hexyl acetate & 1011 & $82.43-818.52$ & $345.54 / 1.13$ \\
\hline (2Z)-2-Hexen-1-yl acetate & 1016 & $0.00-275.32$ & $72.59 / 0.24$ \\
\hline Heptyl acetate & 1113 & $0.00-22.30$ & $8.38 / 0.03$ \\
\hline Hexyl butyrate & 1192 & $0.00-54.56$ & $17.26 / 0.06$ \\
\hline (E)-Butanoic acid-2-hexenyl ester & 1195 & $1.16-31.02$ & $9.32 / 0.03$ \\
\hline Ethyl octoate & 1196 & $0.00-0.54$ & $0.07 /-$ \\
\hline Octyl acetate & 1210 & $0.00-4.61$ & $1.39 /-$ \\
\hline Acetic acid-2-phenylethyl ester & 1258 & $0.00-22.06$ & $5.85 / 0.02$ \\
\hline n-Butyric acid 2-ethylhexyl ester & 1317 & $0.00-21.71$ & $7.95 / 0.03$ \\
\hline Lavandulyl propionate & 1375 & $0.00-14.75$ & $1.74 / 0.01$ \\
\hline Hexanoic acid hexyl ester & 1384 & $0.00-36.33$ & $9.35 / 0.03$ \\
\hline (E)-Hexanoic acid-2-hexenyl ester & 1391 & $0.00-5.13$ & $1.47 /-$ \\
\hline Formic acid undecyl ester & 1441 & $12.32-61.90$ & $25.53 / 0.08$ \\
\hline Benzoic acid hexyl ester & 1580 & $0.00-13.77$ & $1.60 / 0.01$ \\
\hline $\begin{array}{l}\text { 2,2,4-Trimethyl-1,3-pentanediol } \\
\text { diisobutyrate }\end{array}$ & 1588 & $3.05-33.60$ & $12.06 / 0.04$ \\
\hline Propanoic acid 2-methyl-decyl ester & 1590 & $0.00-2.92$ & $0.63 /-$ \\
\hline Alcohols & & $46.52-1214.99$ & $315.82 / 1.04$ \\
\hline 1-Hexanol & 868 & $0.00-632.22$ & $166.87 / 0.55$ \\
\hline (E)-2-Octen-1-ol & 1067 & $0.00-2.60$ & $0.55 /-$ \\
\hline 1-Octanol & 1071 & $12.73-97.24$ & $31.76 / 0.10$ \\
\hline (Z)-3-Nonen-1-ol & 1156 & $0.00-5.42$ & $0.62 /-$ \\
\hline 1-Nonanol & 1173 & $13.23-147.34$ & $45.37 / 0.15$ \\
\hline 1-methyl-4-(1-methylethyl)-Cyclohexanol & 1178 & $0.00-35.01$ & $2.92 / 0.01$ \\
\hline 9-Decen-1-ol & 1262 & $0.00-25.53$ & $4.39 / 0.01$ \\
\hline 1-Decanol & 1273 & $0.00-38.34$ & $10.15 / 0.03$ \\
\hline 1-Dodecanol & 1473 & $7.35-52.17$ & $16.38 / 0.05$ \\
\hline 1-Tetradecanol & 1676 & $7.66-144.20$ & $29.42 / 0.10$ \\
\hline 1-Hexadecanol & 1880 & $0.00-54.61$ & $8.18 / 0.03$ \\
\hline 1-Octadecanol & 2082 & $0.00-17.92$ & $2.12 / 0.01$ \\
\hline Terpenes & & $74.90-1220.67$ & 482.98/1.59 \\
\hline$\alpha$-Thujene & 929 & $1.93-15.79$ & $5.98 / 0.02$ \\
\hline D-Limonene & & $34.16-937.00$ & $357.05 / 1.17$ \\
\hline$\gamma$-Terpinene & 1060 & $0.00-13.83$ & $5.24 / 0.02$ \\
\hline Linalool & 1099 & $2.03-9.05$ & $4.75 / 0.02$ \\
\hline Isophorone & 1124 & $0.00-67.36$ & $6.49 / 0.02$ \\
\hline trans-Limonene oxide & 1138 & $0.00-7.14$ & $0.79 /-$ \\
\hline L- $\alpha$-Terpineol & 1190 & $0.00-18.46$ & $4.62 / 0.02$ \\
\hline Geraniol & 1255 & $0.00-4.36$ & $0.96 /-$ \\
\hline cis-Geranylacetone & 1435 & $0.00-65.67$ & $17.84 / 0.06$ \\
\hline cis- $\beta$-Farnesene & 1444 & $0.00-0.15$ & $0.01 /-$ \\
\hline Humulene & 1454 & $0.00-31.44$ & $9.76 / 0.03$ \\
\hline (E)-2-Dodecenal & 1468 & $0.00-8.26$ & $1.02 /-$ \\
\hline$(Z, E)$ - $\alpha$-Farnesene & 1491 & $0.00-2.96$ & $0.25 /-$ \\
\hline$\alpha$-Farnesene & 1508 & $0.00-277.18$ & $54.17 / 0.18$ \\
\hline$\beta$-Curcumene & 1514 & $0.00-3.80$ & $0.97 /-$ \\
\hline D-Nerolidol & 1544 & $0.00-29.25$ & $4.73 / 0.02$ \\
\hline Nerolidol & 1554 & $0.00-14.44$ & $3.04 / 0.01$ \\
\hline Viridiflorol & 1591 & $0.00-23.10$ & $3.79 / 0.01$ \\
\hline$\alpha$-Bulnesene & & $0.00-6.57$ & $1.51 /-$ \\
\hline Others & & $502.16-15082.46$ & 2197.67/7.22 \\
\hline 1,2-dimethyl-Benzene & 887 & $0.00-108.07$ & $31.80 / 0.10$ \\
\hline methoxy-phenyl-Oxime & & $3.12-374.30$ & $120.12 / 0.39$ \\
\hline
\end{tabular}


Table 3. Cont.

\begin{tabular}{|c|c|c|c|}
\hline Compounds & etention Index (RI) & $\begin{array}{c}\text { Concentration Range } \\
(\mu \mathrm{g} / \mathrm{kg} \text { FW })\end{array}$ & $\begin{array}{c}\text { Average Concentration } \\
(\mu \mathrm{g} / \mathrm{kg} \text { FW)/Percentage } \\
\text { of Total Volatiles }(\%)\end{array}$ \\
\hline$(E, E)-2,4$-Hexadienal & 911 & $0.00-1045.21$ & $206.89 / 0.68$ \\
\hline (E)-4-Oxohex-2-enal & 958 & $55.12-1815.23$ & $309.67 / 1.02$ \\
\hline Phenol & 980 & $0.00-0.41$ & $0.07 /-$ \\
\hline Hexanoic acid & 990 & $0.00-202.81$ & $56.68 / 0.19$ \\
\hline$p$-Cymene & 1025 & $0.00-60.38$ & $11.66 / 0.04$ \\
\hline Benzeneacetaldehyde & 1045 & $2.11-22.32$ & $7.34 / 0.02$ \\
\hline \multicolumn{2}{|l|}{ (Z)-1-ethoxy-4-methyl-2-Pentene } & $3.52-1941.80$ & $354.24 / 1.16$ \\
\hline 1-methyl-4-(1-methylethylidene)-Cyclohexene & 1088 & $0.00-2.22$ & $0.23 /-$ \\
\hline 2-ethenyl-1,4-dimethyl-Benzene & 1090 & $0.00-0.37$ & $0.03 /-$ \\
\hline 2-Nonanone & 1092 & $0.00-156.99$ & $31.20 / 0.10$ \\
\hline Undecane & 1100 & $0.00-8.23$ & $3.08 / 0.01$ \\
\hline 1,2,4,5-tetramethyl-Benzene & 1116 & $0.00-35.93$ & $12.78 / 0.04$ \\
\hline Benzoic acid & 1170 & $0.00-103.50$ & $12.65 / 0.04$ \\
\hline Naphthalene & 1182 & $2.04-26.36$ & $7.28 / 0.02$ \\
\hline Dodecane & 1200 & $9.03-77.73$ & $34.46 / 0.11$ \\
\hline (Z)-3,7-dimethyl-2,6-Octadienal & 1240 & $0.00-4.56$ & $2.05 / 0.01$ \\
\hline Nonanoic acid & 1273 & $0.00-26.95$ & $4.73 / 0.02$ \\
\hline 2,6,11-trimethyl-Dodecane & 1275 & $0.00-36.70$ & $10.34 / 0.03$ \\
\hline Tridecane & 1300 & $7.44-58.40$ & $18.34 / 0.06$ \\
\hline 2,3,5,8-tetramethyl-Decane & 1318 & $0.00-27.36$ & $7.97 / 0.03$ \\
\hline Tetradecane & 1400 & $18.28-91.39$ & $35.06 / 0.12$ \\
\hline Pentadecane & 1500 & $0.00-231.63$ & $60.09 / 0.20$ \\
\hline 2,6,10-trimethyl-Tetradecane & 1539 & $0.00-19.23$ & $6.37 / 0.02$ \\
\hline 5-methyl-Pentadecane & 1547 & $2.21-45.84$ & $7.54 / 0.02$ \\
\hline 5,8-Diethyldodecane & 1572 & $3.79-34.53$ & $9.61 / 0.03$ \\
\hline Hexadecane & 1600 & $5.84-64.97$ & $15.45 / 0.05$ \\
\hline 6,9-Heptadecadiene & 1667 & $0.00-2.30$ & $0.56 /-$ \\
\hline 1-Hydroxycyclohexyl phenyl ketone & 1687 & $9.28-199.96$ & $39.17 / 0.13$ \\
\hline Tetradecanoic acid & 1768 & $0.00-1225.67$ & $102.14 / 0.34$ \\
\hline 2,6,11,15-tetramethyl-Hexadecane & 1792 & $0.19-33.98$ & $5.64 / 0.02$ \\
\hline Pentadecanoic acid & 1867 & $0.00-1175.82$ & $98.01 / 0.32$ \\
\hline Nonadecane & 1900 & $3.85-94.82$ & $18.62 / 0.06$ \\
\hline 9-Hexadecenoic acid & 1942 & $0.00-1610.17$ & $135.11 / 0.44$ \\
\hline$n$-Hexadecanoic acid & 1968 & $0.00-3839.76$ & $319.98 / 1.05$ \\
\hline Eicosane & 2000 & $0.00-52.30$ & $6.24 / 0.02$ \\
\hline Heptadecanoic acid & 2071 & $0.00-129.25$ & $10.77 / 0.04$ \\
\hline Heneicosane & 2100 & $8.04-295.40$ & $47.09 / 0.15$ \\
\hline Oleic Acid & 2141 & $0.00-404.28$ & $33.69 / 0.11$ \\
\hline Total & & 13098.35-79188.69 & $30444.88 / 100.00$ \\
\hline
\end{tabular}

Note: ' - ' in the line of the percentage means that the percentage of compounds was lower than $0.005 \%$; bold numbers were the total contents of different kinds of substances; the retention index was acquired on the semi-standard non-polar.

\subsection{OPLS-DA Analysis on Korla Pear Fruit from 12 Orchards}

In order to discriminate Korla pear fruit with different sensory qualities, the GC-MS data including the concentrations of primary metabolites and volatiles were analyzed by using OPLS-DA. As shown in Figure 1, the pear fruit could be classified into two groups, with one corresponding to high sensory quality (sensory ranks: 1-9) and the other corresponding to low sensory quality (sensory ranks: 10-12). As a result, nine metabolites with VIP values higher than 1.5, including L-(+)-tartaric acid, malic acid, D-(-)-fructofuranose, $\alpha$-bulnesene, fructose, psicopyranose, L-proline, glucose and L- $\alpha$-terpineol, were obtained and listed in the Supplementary Material (Table S9). 


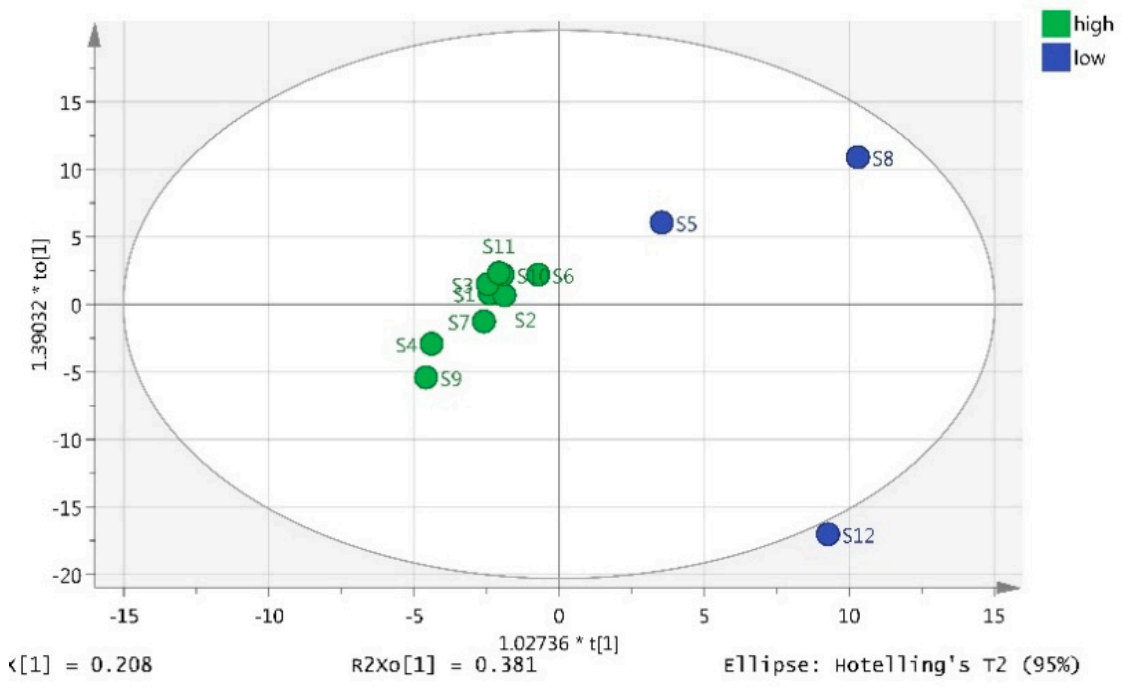

Figure 1. Score plot of OPLS-DA models with the statistical parameters ( $R 2 X=0.208, R 2 Y=1.000$, $\mathrm{Q} 2=0.321)$ for the classification of Korla pear fruit. High: pear fruit ranked 1-9 in sensory score; Low: pear fruit ranked 10-12 in sensory score.

\subsection{Correlation Analysis between Sensory Scores and Metabolites}

The similarity values and metabolite concentrations of Korla pear fruit from 12 orchards were subjected to Pearson correlation analysis. Figure 2 presents part of the correlation coefficients. None of the primary metabolites except for $\mathrm{L}-(+)$-tartaric acid was found to be correlated with sensory scores. For volatiles, hexanoic acid, trans-limonene oxide and 2,2,4-trimethyl-1,3-pentanediol diisobutyrate showed negative correlations with sensory scores.

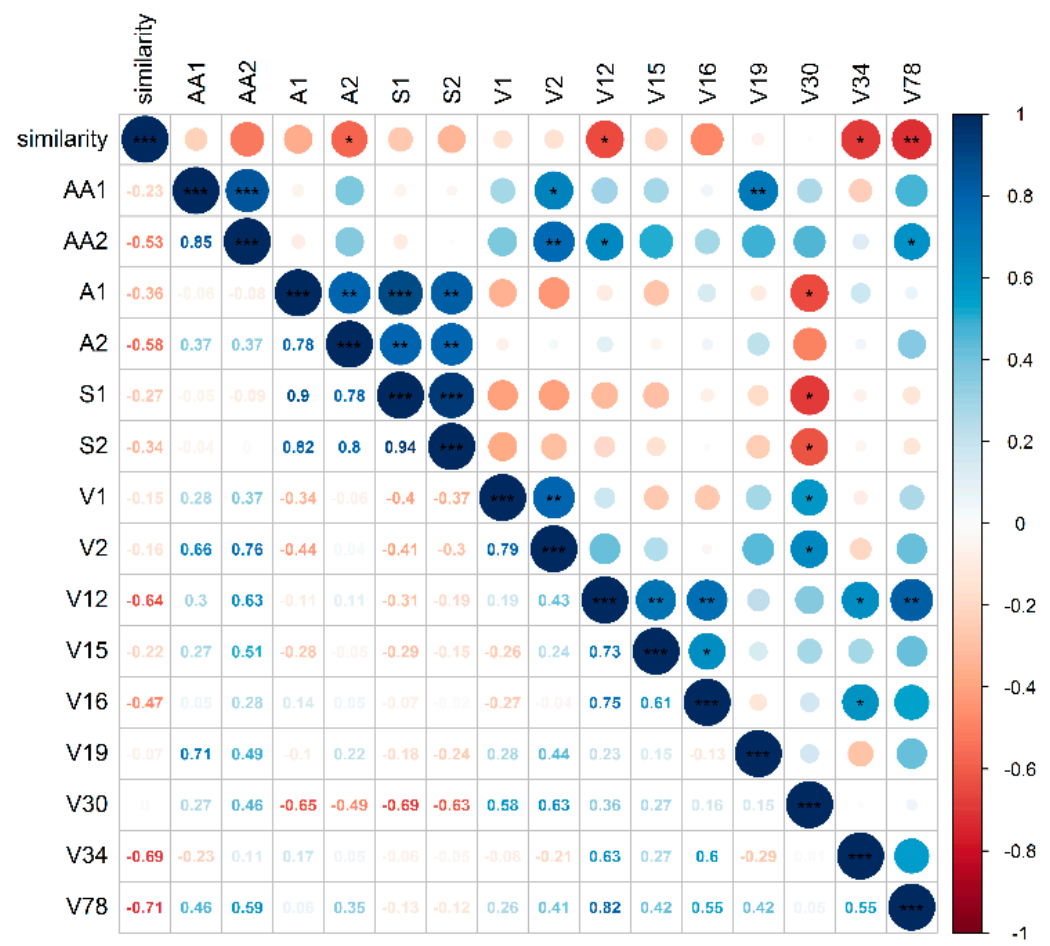

Figure 2. Correlation analysis of sensory scores and metabolites. AA1 and AA2 were amino acids, A1 and A2 were organic acids, S1 and S2 were soluble sugars listed in Table S6; V1, V2, V12, V15, V16, V19, V30, V34, V78 were volatiles presented in Table S7. * Significantly correlated at the 0.05 level. ** Significantly correlated at the 0.01 level. ${ }^{* * *}$ Significantly correlated at the 0.001 level. 


\section{Discussion}

\subsection{Important Sensory Quality Attributes Defined in the Study}

The Kuerle district is thought to be a traditionally superior production area of Korla pear, and the pear fruit are sold out quickly in each season with better prices. However, pear fruit from this area did not exhibit its superiority in this study. Moreover, the ranks of sensory quality for pear fruit from the same orchard were not consistent in two consecutive seasons. For example, the rank of S5 changed from the twelfth to the fourth, while that of S6 shifted from the third to the eleventh, which may be ascribed to the variations in the fruiting of trees due to poor orchard management. Additionally, there were only subtle differences among pear fruit from 12 orchards as most samples were classified into F4/Good. Although the deficiency in the precision of evaluation by panelists could be somewhat compensated by using fuzzy logic, differences between pear samples had not been amplified as expected, possibly because of their identical genotype.

Currently, the price of Korla pear in the market mainly depends on the fruit size and shape, which is also the case for many other fruits, mainly because other attributes such as 'aroma' can hardly be quantified by a unified standard. However, 'mouth feel' and 'aroma' were more important than other three attributes in this study, probably because all the panelists chosen for the test were young college students with basic knowledge of horticultural products. Their choices may partly represent the preference of young people. It could be speculated that the flavor and mouth feel may become important sensory quality attributes of Korla pear in the future, and the findings in this study may promote the improvement of market standards for the production of Korla pear.

\subsection{Metabolites Detected in Korla Pear}

The amino acid content determined in this study was generally lower than that previously described [3]. The lack of acid hydrolysis process may lead to insufficient release of amino acids. Compared with the results of a previous study [27], the acids were reduced while the sugars showed no significant change in the period from commercial maturity (160 DAFB, days after full bloom) to physiological maturity (180 DAFB) in the pulp of Korla pear. As a result, there was a further increase in sugar/acid ratio at physiological maturity of 180 DAFB. The high sugar/acid ratio may be the major reason for 'mouth feel' to rank the first in the five quality attributes.

The volatiles previously reported to be associated with the flavor of Korla pear, such as hexanal, (E)-2-hexenal, hexyl acetate, and $\alpha$-farnesene, were also detected in this study $[8,12,13]$. The number of volatiles detected in the fruit from different orchards ranged from 57 (in S5) to 84 (in S8), implying that the Korla pear fruit from different orchards had unique volatile profiles. As for different developmental stages, the total volatile content rose by nearly 10 folds from commercial maturity to physiological maturity [27]. Since all volatiles of Korla pear showed sharp increases in this period, it could be speculated that the period from 160 DAFB to 180 DAFB is a crucial period for the formation of its flavor. For Korla pear, the primary metabolite profiles were relatively similar among all samples, while volatile profiles were diverse, indicating that volatiles are more susceptible to environment factors.

\subsection{Association between Metabolites and the Sensory Quality of Korla Pear}

Four metabolites, including L-(+)-tartaric acid, hexanoic acid, trans-limonene oxide and 2,2,4-trimethyl-1,3-pentanediol diisobutyrate (TXIB), were found to be negatively correlated with sensory scores. TXIB was known as a kind of plasticizer and could be an ambient environmental pollutant which contribute to indoor odor and irritation [28], it's sensory perception fitted well with the negative correlation. As TXIB was not a natural material, it was very possible to be a pollutant from human activities as the local farmers often spray something to help remove the calyx of Korla pear and shaping pear beautiful. However, there may be some more potential connections between metabolites and sensory quality or among various metabolites. As metabolites in food generally form a comprehensive flavor in various proportions, a single compound has limited impact on fruit quality. 
Other indicators such as the ratio between some key flavor metabolites can be taken into account in future research.

\section{Materials and Methods}

\subsection{Plant Materials}

Fruit of Korla pear grown in the Kashi, Akesu and Kuerle districts in Circum-Tarim Basin, South Xinjiang of China were harvested from 12 different orchards (Figure 3) at two consecutive seasons in 2018 and 2019, respectively. All samples with representative size and shape of each orchard were harvested at commercial maturity on around 160 DAFB. For each orchard, thirty fruit were used for sensory evaluation in 2018 and 2019, respectively, and fifteen were used for the analysis of primary metabolites and volatiles in 2018.

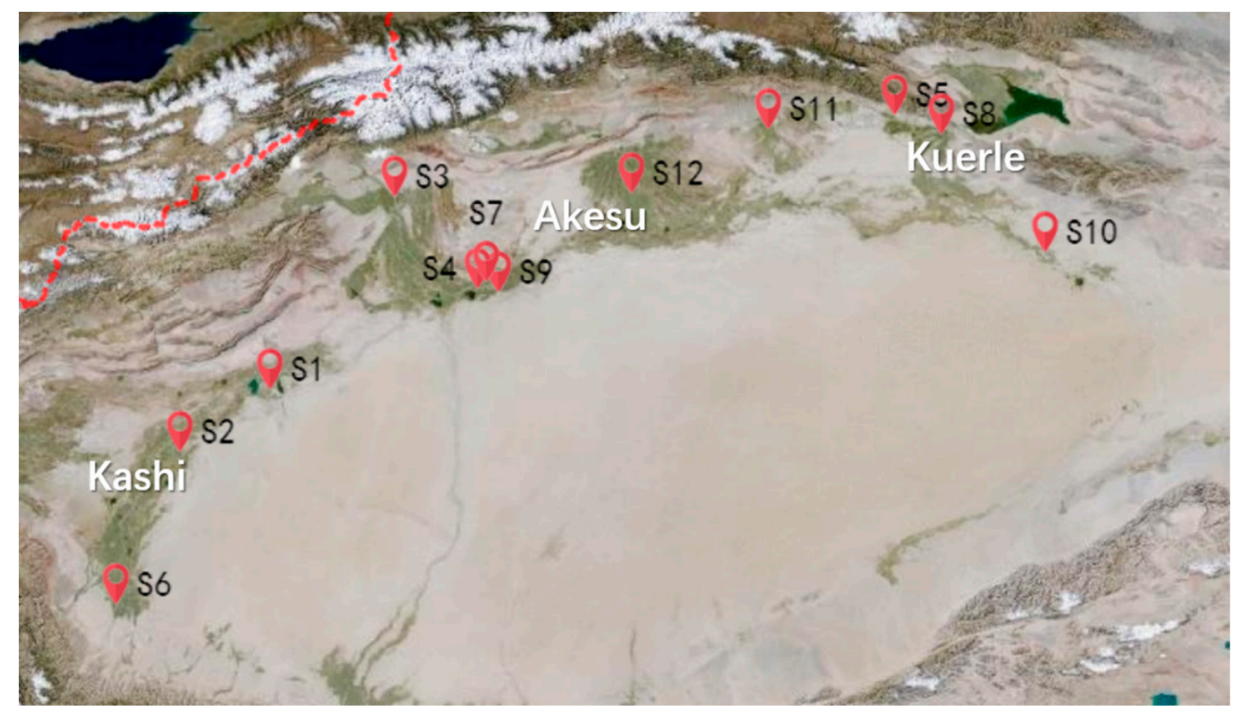

Figure 3. Geographic coordinates of the 12 pear orhchards in Xinjiang.

\subsection{Chemicals and Reagents}

Methanol of HPLC grade was purchased from Fisher Scientific (Fair lawn, NJ, USA). Standard of $n$-paraffins mixture (C7-C40) were purchased from ANPEL Laboratory Technologies (Shanghai) Inc. (Shanghai, China). Sodium chloride was obtained from Sinopharm Chemical Reagent Co., Ltd. (Shanghai, China). Methyl nonanoate, Ribitol, $N$-methyl-N-(trimethylsilyl) trifluoroacetamide (MSTFA) and methoxamine hydrochloride were purchased from Sigma Aldrich (Saint Louis, MO, USA). All the chemicals and reagents were of analytical grade.

\subsection{Sensory Evaluation of Korla Pear Fruit}

Korla pear fruit were evaluated using the fuzzy logic model described in previous studies [17-19] in the Sensory Evaluation Laboratory of Key Laboratory of Horticultural Plant Biology (Ministry of Education), Huazhong Agricultural University. Sixty healthy panelists (at the age of 20-30 with equal numbers of male and female) were selected from untrained students in the College of Horticulture and Forestry Science, Huazhong Agricultural University, who were representatives of those educated young consumers with certain horticultural knowledge. The quality attributes selected for sensory evaluation included 'peel color', 'fruit shape', 'fruit size', 'aroma' and 'mouth feel'. The above attributes were graded as 'Poor,' 'Fair,' 'medium,' 'Good' or 'Excellent.' The panelists were required to judge the importance of each attribute of the samples at five scales: 'NI' for not important, 'SI' for somewhat important, 'IM' for important, 'HI' for highly important and 'EI' for extremely important. Ten panelists were randomly selected to participate in each round of testing. In each evaluation of one sample, 
five fruit were presented to each panelist and then the panelist gave his evaluation results about the five sensory attributes, respectively. The panelists were asked to clean their mouth with water and have a 3 min-rest after tasting each sample in order to eliminate sensory fatigue. Totally, 20 datasets were collected for each sample.

The major steps involved in the fuzzy modeling of sensory evaluation were: (1) calculation of the overall sensory scores in the form of triplets; (2) assessment of membership function on the standard fuzzy scale; (3) estimation of the overall membership function on the standard fuzzy scale; (4) calculation of the similarity values and ranking of the fruit samples from the 12 different orchards. The 5-point sensory scales were composed of 'Poor' ( 00 25), 'Fair' (25 25 25), 'Medium' (50 25 25), 'Good' (75 25 25) and 'Excellent' (100 25 0) (Figure 4). The first number of the triplets indicates the coordinate of the abscissa where the value of the membership function is 1 , while the second and the third numbers represent the distance of the first number to the left and right, respectively, where the value of the membership function is 0 .

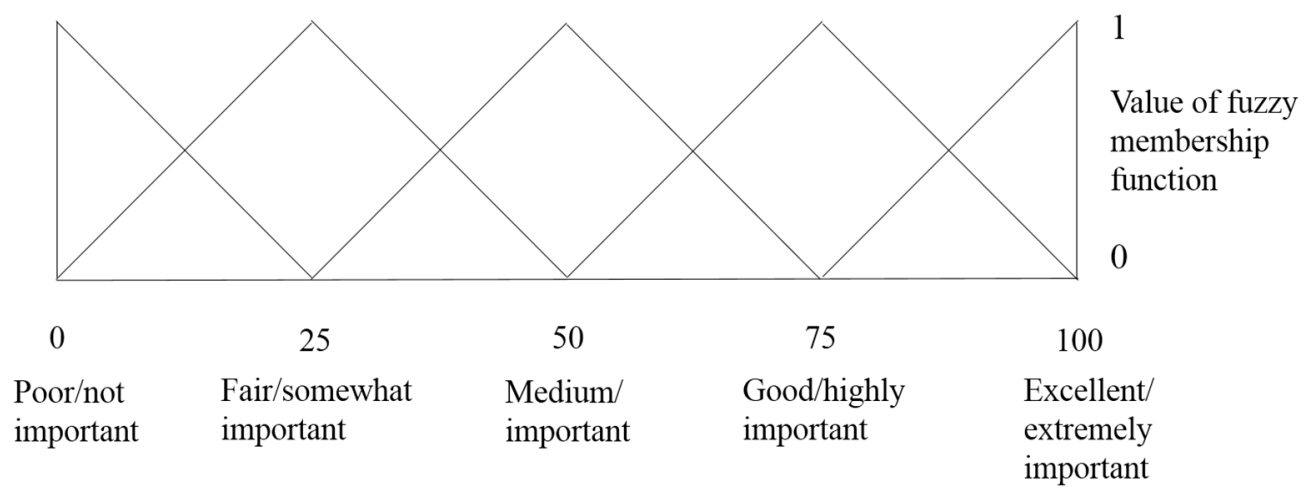

Figure 4. Triangular membership function distribution pattern of 5-point scale [17].

\subsubsection{Calculation of the Overall Quality Scores}

For each sample, the triplets corresponding to sensory quality attributes were calculated by the following equation:

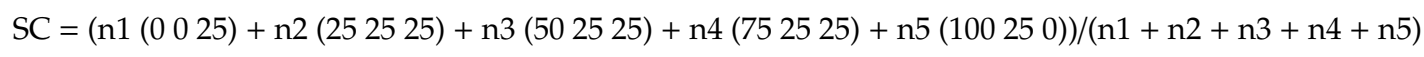

where SC is the triplet for 'peel color' attribute, ' $n 1$ ' to ' $n 5^{\prime}$ are the numbers of panelists who chose a certain grade for each sensory quality attribute of each sample. The first number was normalized to obtain the triplets for relative weightage.

After that, triplets for all sensory quality attributes were generated, and the triplets for the overall quality scores could be calculated by the following equation:

$$
\mathrm{SO}=\mathrm{SC} \times \mathrm{QCr}+\mathrm{SS} \times \mathrm{QSr}+\mathrm{SD} \times \mathrm{QDr}+\mathrm{SA} \times \mathrm{QAr}+\mathrm{ST} \times \mathrm{QTr}
$$

where $\mathrm{SO}$ is the overall quality triplet, ' $\mathrm{C}$ ' is for 'peel color', ' $\mathrm{S}$ ' for 'fruit shape', ' $\mathrm{D}$ ' for 'fruit size', ' $\mathrm{A}$ ' for 'aroma', ' $\mathrm{T}$ ' for 'mouth feel'. SC, SS, SD, SA and ST are the triplets for quality attributes, respectively. 'QCr', 'QSr', 'QDr', 'QAr' and 'QTr' represent the triplets for relative weightage of their corresponding quality attributes, respectively. The multiplication of two triplets was conducted as

$$
(a b c) \times(d e f)=(a \times d a \times e+d \times b a \times f+d \times c)
$$




\subsubsection{Calculation of Membership Function on the Standard Fuzzy Scale}

The standard fuzzy scale of (F1, F2, F3, F4, F5, F6) follows the triangular distribution pattern, where the maximum value of membership function is 1 , and the values were defined by a set of 10 numbers.

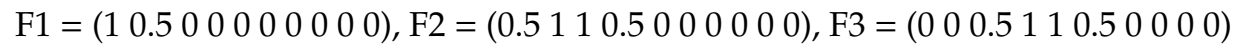

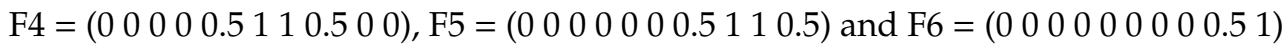

For each sample with a triplet, its corresponding overall membership function value was calculated with the formulas below:

$$
\begin{gathered}
\text { If }(a-b)<x<a, B x=(x-(a-b)) / b ; \text { if } a<x<(a+c), B x=((a+c)-x) / c ; \\
\text { if } x=a, B x=1 \text {; if } x<(a-b) \text { or } x>(a+c), B x=0 .
\end{gathered}
$$

For each sample and its triplets, the values of the membership function Bx at $0,10,20,30,40$, 50, 60, 70, 80, 90 and 100 could be obtained through the above formula. The membership function value of samples on the standard fuzzy scale for matrix B1 to B12 would be given a set of 10 numbers, which were the maximum values of $B x$ at 10 intervals of $0<x<10$ to $90<x<100$, respectively.

\subsubsection{Calculation of Similarity Values and Ranking of the Korla Pear Fruit from Different Orchards}

The similarity values of pear fruit from different orchards were obtained with the following equation:

$$
\mathrm{Sm}=\left(\mathrm{F} \times \mathrm{B}^{\prime}\right) /\left(\operatorname{Max}\left(\mathrm{F} \times \mathrm{F}^{\prime} \text { and } \mathrm{B} \times \mathrm{B}^{\prime}\right)\right)
$$

where $\mathrm{Sm}$ is the similarity value of the samples, and $\mathrm{F}^{\prime}$ and $\mathrm{B}^{\prime}$ are the transpose of matrix $\mathrm{F}$ and $\mathrm{B}$, respectively.

Six similarity values would be obtained for each sample, and then applied to the ranking of the pear fruit from different orchards.

\subsection{Analysis of Primary Metabolites by Using GC-MS}

The seeds, stones and peels were first removed, and then the fruit flesh was cubed. Primary metabolites in the cubes of Korla pear fruit were detected by GC-MS as described in previous studies $[29,30]$ with minor modifications. The relative concentration of compounds was calculated by comparison with the internal standard. The cubes were quickly ground into powder with liquid nitrogen. Then, $0.30 \mathrm{~g}$ powder was thoroughly mixed with $3 \mathrm{~mL}$ methanol containing $0.02 \mathrm{mg} / \mathrm{mL}$ ribitol as the internal standard. After shaking and ultrasonic treatment for $30 \mathrm{~min}$, the mixture was put into a thermostated water bath at $70{ }^{\circ} \mathrm{C}$ for $15 \mathrm{~min}$ and centrifuged at $5000 \mathrm{~g}$ for $15 \mathrm{~min}$. Then, $100 \mu \mathrm{L}$ supernatant were collected and vacuum-concentrated. Metabolites were trimethylsilylation (TMS) derivatized before GC-MS analysis. Samples were dissolved in $80 \mu \mathrm{L}$ methoxamine hydrochloride (20 mg/mL in pyridine), incubated for $90 \mathrm{~min}$ at $37^{\circ} \mathrm{C}$, and then reacted with $80 \mu \mathrm{L}$ of MSTFA for $30 \mathrm{~min}$ at $37^{\circ} \mathrm{C}$. After that, $1 \mu \mathrm{L}$ of each sample was injected into the gas chromatography (Thermo Fisher Scientific, Waltham, MA, USA) onto a fused-silica capillary column $(30 \mathrm{~m} \times 0.25 \mathrm{~mm}$ i.d., $0.25 \mu \mathrm{m}$ DB-5MS stationary phase). The temperature program of GC was as follows: $100^{\circ} \mathrm{C}$ for $1 \mathrm{~min}$, heated to $184{ }^{\circ} \mathrm{C}$ at $3{ }^{\circ} \mathrm{C} / \mathrm{min}$, heated to $190^{\circ} \mathrm{C}$ at $0.5^{\circ} \mathrm{C} / \mathrm{min}$ and kept for $1 \mathrm{~min}$, heated to $280^{\circ} \mathrm{C}$ at $15^{\circ} \mathrm{C} / \mathrm{min}$ and kept for $5 \mathrm{~min}$, with the pulsed split injector temperature held at $230{ }^{\circ} \mathrm{C}$ as the split ratio was 10 , and the carrier gas was set at a flow rate of $1.2 \mathrm{~mL} / \mathrm{min}$. The conditions for mass spectrometer were: electron ionization source, electron energy of $70 \mathrm{eV}$; ionization temperature $260^{\circ} \mathrm{C}$, transfer line temperature $280{ }^{\circ} \mathrm{C}$ and scanning range of 40 to $650 \mathrm{amu}$.

The compounds detected by using GC-MS was identified by comparing their mass spectra with the NIST MS Search 2.3. 
Semiquantitative determinations were conducted using ribitol as an internal standard. The contents of volatiles were calculated from the GC TIC peak areas related to the GC TIC peak area of the internal standard.

\subsection{Volatile Determination by Headspace Solid Phase Microextraction-GC-MS}

Since more than $90 \%$ of total volatiles were found in the peel, the volatiles in the peel of Korla pear were determined using a previously described method [27]. The relative concentration of compounds was calculated by comparison with the internal standard. The peel tissue was quickly ground into powder with liquid nitrogen. Then, $2.50 \mathrm{~g}$ powder was placed in $15-\mathrm{mL}$ headspace vials together with $5 \mathrm{~mL} 30 \% \mathrm{NaCl}$ solution containing $0.1 \mu \mathrm{L} / 100 \mathrm{~mL}$ methyl nonanoate as the internal standard. The vials were then placed on the platform for automatic sample injection. The sample in the vial was incubated at $45{ }^{\circ} \mathrm{C}$ for $15 \mathrm{~min}$, and the Divinylbenzene/Carboxen/Polydimethylsiloxane fiber $\left(50 / 30 \mu \mathrm{m}, \mathrm{DVB} / \mathrm{CAR}\right.$ on PDMS, $2 \mathrm{~cm}$ ) was conditioned at $250^{\circ} \mathrm{C}$ for $5 \mathrm{~min}$ for each sample before testing. Then the volatiles in the headspace of the vials were collected for $15 \mathrm{~min}$ by using the fiber. Subsequently, the fiber was removed from the vial and immediately inserted into the GC injection port to desorb the volatiles at $250^{\circ} \mathrm{C}$ for $5 \mathrm{~min}$. The analysis was performed with gas chromatography (Thermo Fisher Scientific, Waltham, MA, USA) equipped with a TRACE TR-5 MS capillary column $(30 \mathrm{~m} \times 0.25 \mathrm{~mm} \times 0.25 \mu \mathrm{m}$, Thermo Scientific, Bellefonte, PA, USA). Helium was used as the carrier gas at a constant flow rate of $1 \mathrm{~mL} / \mathrm{min}$. The temperature program of GC was as follows: $40^{\circ} \mathrm{C}$ for $3 \mathrm{~min}$, heated to $160^{\circ} \mathrm{C}$ at $3{ }^{\circ} \mathrm{C} / \mathrm{min}$ and kept for $1 \mathrm{~min}$, heated to $200^{\circ} \mathrm{C}$ at $5^{\circ} \mathrm{C} / \mathrm{min}$ and kept for $1 \mathrm{~min}$, heated to $240{ }^{\circ} \mathrm{C}$ at $8{ }^{\circ} \mathrm{C} / \mathrm{min}$ e and kept for $1 \mathrm{~min}$, with the pulsed splitless injector temperature held at $250^{\circ} \mathrm{C}$. The conditions for mass spectrometer were: electron ionization source, electron energy of $70 \mathrm{eV}$; ionization temperature $230^{\circ} \mathrm{C}$, transfer line temperature $230{ }^{\circ} \mathrm{C}$ and scanning range of 30 to $550 \mathrm{amu}$.

The compounds detected by using GC-MS was identified by comparing their mass spectra with the NIST MS Search 2.3. RIs was calculated basing on the retention time of C7-C40 alkane series under the same chromatographic conditions.

Semiquantitative determinations were conducted using methyl nonanoate as an internal standard. The contents of volatiles were calculated from the GC TIC peak areas related to the GC TIC peak area of the internal standard.

\subsection{Statistical Analysis}

The results were presented as means of three biological replicates \pm standard deviation (SD). SIMCA 14.1, RStudio and Excel 2016 were used for all statistical analyses. Supervised orthogonal partial least-squares discriminate analysis (OPLS-DA) was applied to discriminate Korla pear fruit from different orchards with different sensory scores by using SIMCA 14.1. The corresponding variable importance in projection (VIP) value was calculated in the OPLS-DA model, which represented the differences of the variables. Compounds that played important roles in the grouping of fruit were picked out when the VIP value was higher than 1.5. Pearson correlation analysis was conducted with similarity values and metabolite concentrations using RStudio.

\section{Conclusions}

In the present study, the sensory quality of Korla pear fruit from 12 orchards in Circum-Tarium Basin in two consecutive seasons was ranked by using the fuzzy logic model. The ranks of sensory quality attributes indicated that 'mouth feel' and 'aroma' have great contribution to the fruit quality of Korla pear. Hexanal, (E)-2-hexenal, nonanal, D-limonene, (Z)-3-hexen-1-yl acetate and hexyl acetate were identified as the major volatiles in Korla pear. Notably, L-(+)-tartaric acid, hexanoic acid, trans-limonene oxide and 2,2,4-trimethyl-1,3-pentanediol diisobutyrate were found to be negatively correlated with the sensory similarity values. 
Supplementary Materials: The following are available online. Table S1: Sensory scores for pear samples and the corresponding triplets; Table S2: Preferences given by panelists and corresponding triplets for relative weightage; Table S3: Overall triplets of pear samples; Table S4: Values of overall membership function of pear samples; Table S5: Similarity values of quality attributes for Korla pear; Table S6: Primary metabolites detected in the pulp of Korla pear by using GC-MS; Table S7: Volatiles detected in the peel of Korla pear by using HS-SPME-GC-MS; Table S8: Seven volatile compounds uniquely detected in specific orchards in 2018; Table S9: List of potential chemical markers.

Author Contributions: Study design, J.X. and J.W.; financial support, C.W., J.X. and J.W.; sample collection, Z.T., C.W., and J.W.; data collection, S.X. and H.Z. (Haipeng Zhang); data analysis, H.Z. (Hongyan Zhang), S.X. and Y.L.; figures, Y.L.; literature search, Y.L.; writing, X.X.; writing, Y.L. and J.X. All authors have read and agreed to the published version of the manuscript.

Funding: This research was funded by the XPCC South Xinjiang Key Industry Support Plan (2017DB006-2).

Conflicts of Interest: The authors declare there is no conflict of interest in this study.

\section{References}

1. Qin, G.; Tao, S.; Cao, Y.; Wu, J.; Zhang, H.; Huang, W.; Zhang, S. Evaluation of the volatile profile of 33 Pyrus ussuriensis cultivars by HS-SPME with GC-MS. Food Chem. 2012, 134, 2367-2382. [CrossRef] [PubMed]

2. Yao, G.; Yang, Z.; Zhang, S.; Cao, Y.; Liu, J.; Wu, J. Characteristics of components and contents of organic acid in pear fruits from different cultivated species. Sci. Agric. Sin. 2014, 41, 755-764. [CrossRef]

3. Chen, J.; Wang, Z.; Wu, J.; Wang, Q.; Hu, X. Chemical compositional characterization of eight pear cultivars grown in China. Food Chem. 2007, 104, 268-275. [CrossRef]

4. Chen, Y.; Yin, H.; Wu, X.; Shi, X.; Qi, K.; Zhang, S. Comparative analysis of the volatile organic compounds in mature fruits of 12 Occidental pear (Pyrus communis L.) cultivars. Sci. Hortic. 2018, 240, 239-248. [CrossRef]

5. Yao, G.; Zhang, S.; Cao, Y.; Liu, J.; Wu, J.; Yuan, J.; Zhang, H.; Xiao, C. Characteristics of Components and Contents of Soluble Sugars in Pear Fruits from Different Species. Sci. Agric. Sin. 2010, 43, 4229-4237. [CrossRef]

6. Wang, Y.; Liu, Y.; Zhang, Y.; Xu, Z. Quality evaluation of mixed brewed perries based on PCA and sensory evaluation. Front. Agric. China 2011, 5, 529-533. [CrossRef]

7. Hudina, M.; Colarič, M.; Štampar, F. Primary metabolites in the leaves and fruits of three pear cultivars during the growing season. Can. J. Plant Sci. 2007, 87, 327-332. [CrossRef]

8. Chen, J.; Lü, J.; He, Z.; Zhang, F.; Zhang, S.; Zhang, H. Investigations into the production of volatile compounds in Korla fragrant pears (Pyrus sinkiangensis Yu). Food Chem. 2020, 302, 125337. [CrossRef]

9. Li, F.; Zhang, H.; He, Z.; Tao, S.; Li, G.; Zhang, S. Effects of bagging on soluble sugars, organic acids, and aroma compounds in Pyrus sinkiangensis 'Korla Xiangli' fruit. Acta Hortic. Sin. 2016, 41, 1443-1450. [CrossRef]

10. Ji, L.C.; Ji, H.W.; Wang, Q.; Deng, H.; Xiao, S.H. Changes in the volatile compounds and chemical and physical properties of Kuerle fragrant pear (Pyrus serotina Reld) during storage. J. Agric. Food Chem. 2006, 54, 8842-8847. [CrossRef]

11. Pan, Y.; Meng, X.; Che, F.; Xue, S.; Zhang, T.; Zhao, S.; Liao, K. Metabolic Profiles of Sugar Metabolism and Respiratory Metabolism of Korla Pear (Pyrus sinkiangensis Yu) Throughout Fruit Development and Ripening. Sci. Agric. Sin. 2016, 49, 3391-3412. [CrossRef]

12. Chen, J.; Zhou, S.; Wang, Q.; Hu, X. Analysis of aroma components of Xinjiang kuerle fragrant pear. Food Sci. Technol. 2007, 6, 114-117. [CrossRef]

13. Tu, J.; Qin, Z.; Li, X.; Liu, X.; Yang, F.; Zhu, H. Analysis of Fruit Aromatic Components of Pyrus pyrifolia Nakai and P. sinkiangensis Yu by GC-MS. Hubei Agric. Sci. 2011, 50, 3186-3190. [CrossRef]

14. Debjani, C.; Das, S.; Das, H. Aggregation of sensory data using fuzzy logic for sensory quality evaluation of food. J. Food Sci. Technol. 2013, 50, 1088-1096. [CrossRef]

15. Vivek, K.; Subbarao, K.V.; Routray, W.; Kamini, N.R.; Dash, K.K. Application of Fuzzy Logic in Sensory Evaluation of Food Products: A Comprehensive Study. Food Bioprocess Technol. 2020, 13, 1-29. [CrossRef]

16. Zare, D.; Ghazali, H.M. Assessing the quality of sardine based on biogenic amines using a fuzzy logic model. Food Chem. 2017, 221, 936-943. [CrossRef]

17. Routray, W.; Mishra, H.N. Sensory evaluation of different drinks formulated from dahi (Indian Yogurt) powder using fuzzy logic. J. Food Process. Preserv. 2012, 36, 1-10. [CrossRef]

18. Tahsiri, Z.; Niakousari, M.; Khoshnoudi-Nia, S.; Hosseini, S.M.H. Sensory evaluation of selected formulated milk barberry drinks using the fuzzy approach. Food Sci. Nutr. 2017, 5, 739-749. [CrossRef] 
19. Sinija, V.R.; Mishra, H.N. Fuzzy Analysis of Sensory Data for Quality Evaluation and Ranking of Instant Green Tea Powder and Granules. Food Bioprocess Technol. 2011, 4, 408-416. [CrossRef]

20. Du, X.F.; Kurnianta, A.; McDaniel, M.; Finn, C.E.; Qian, M.C. Flavour profiling of "Marion" and thornless blackberries by instrumental and sensory analysis. Food Chem. 2010, 121, 1080-1088. [CrossRef]

21. Qiu, S.; Wang, J. Application of Sensory Evaluation, HS-SPME GC-MS, E-Nose, and E-Tongue for Quality Detection in Citrus Fruits. J. Food Sci. 2015, 80, S2296-S2304. [CrossRef] [PubMed]

22. Zhu, J.C.; Wang, L.Y.; Xiao, Z.B.; Niu, Y.W. Characterization of the key aroma compounds in mulberry fruits by application of gas chromatography-olfactometry (GC-O), odor activity value (OAV), gas chromatographymass spectrometry (GC-MS) and flame photometric detection (FPD). Food Chem. 2018, 245, 775-785. [CrossRef] [PubMed]

23. Favati, F.; Condelli, N.; Galgano, F.; Caruso, M.C. Extra virgin olive oil bitterness evaluation by sensory and chemical analyses. Food Chem. 2013, 139, 949-954. [CrossRef] [PubMed]

24. Tokitomo, Y.; Steinhaus, M.; Büttner, A.; Schieberle, P. Odor-active constituents in fresh pineapple (Ananas comosus [L.] Merr.) by quantitative and sensory evaluation. Biosci. Biotechnol. Biochem. 2005, 69, 1323-1330. [CrossRef] [PubMed]

25. Jung, K.; Fastowski, O.; Poplacean, I.; Engel, K.H. Analysis and Sensory Evaluation of Volatile Constituents of Fresh Blackcurrant (Ribes nigrum L.) Fruits. J. Agric. Food Chem. 2017, 65, 9475-9487. [CrossRef] [PubMed]

26. Tieman, D.; Zhu, G.; Resende, M.F.R.; Lin, T.; Nguyen, C.; Bies, D.; Rambla, J.L.; Beltran, K.S.O.; Taylor, M.; Zhang, B.; et al. A chemical genetic roadmap to improved tomato flavor. Science 2017, 355, 391-394. [CrossRef] [PubMed]

27. Liu, Y.; Xiang, S.; Wang, J.; Wu, C.; Tang, Z.; Gong, H.; Zhang, X.; Xu, J. GC-MS analyses of volatiles and primary metabolites in Korla Pear fruit. J. Huazhong Agric. Univ. 2020, 39, 44-52. [CrossRef]

28. Kim, J.L.; Elfman, L.; Mi, Y.; Wieslander, G.; Smedje, G.; Norbäck, D. Indoor molds, bacteria, microbial volatile organic compounds and plasticizers in schools-Associations with asthma and respiratory symptoms in pupils. Indoor Air 2007, 17, 153-163. [CrossRef]

29. Sheng, L.; Shen, D.; Yang, W.; Zhang, M.; Zeng, Y.; Xu, J.; Deng, X.; Cheng, Y. GABA Pathway Rate-Limit Citrate Degradation in Postharvest Citrus Fruit Evidence from HB Pumelo (Citrus grandis) $\times$ Fairchild (Citrus reticulata) Hybrid Population. J. Agric. Food Chem. 2017, 65, 1669-1676. [CrossRef]

30. Sheng, L.; Shen, D.; Luo, Y.; Sun, X.; Wang, J.; Luo, T.; Zeng, Y.; Xu, J.; Deng, X.; Cheng, Y. Exogenous $\gamma$-aminobutyric acid treatment affects citrate and amino acid accumulation to improve fruit quality and storage performance of postharvest citrus fruit. Food Chem. 2017, 216, 138-145. [CrossRef]

Sample Availability: Samples of the pear peels and compounds are available from the authors.

Publisher's Note: MDPI stays neutral with regard to jurisdictional claims in published maps and institutional affiliations.

(C) 2020 by the authors. Licensee MDPI, Basel, Switzerland. This article is an open access article distributed under the terms and conditions of the Creative Commons Attribution (CC BY) license (http://creativecommons.org/licenses/by/4.0/). 